\title{
PELACAKAN ALUMNI (TRACER STUDY) JURUSAN \\ MANAJEMEN INFORMATIKA BERBASIS ICT (INFORMATION \& COMMUNICATION TECHNOLOGY)
}

\author{
Oleh \\ Komang Setemen \\ Jurusan Manajemen Informatika, FTK Undiksha
}

\begin{abstract}
Abstrak
Jurusan D3 Manajemen Informatika merupakan salah satu Jurusan di bawah Fakultas Teknik dan Kejuruan Universitas Pendidikan Ganesha. Dari sejak berdirinya tahun 1999 sampai dengan akhir tahun 2007, jurusan ini telah meluluskan kurang lebih 290 orang, dan sebagian besar telah terserap di dunia usaha dan industri, serta ada juga yang terserap sebagai pegawai negeri sipil (PNS). Sejauh ini, pencatatan atau dokumentasi lulusan hanya dilakukan secara tertutup yang artinya hanya ada catatan akhir dari para lulusan yang tersimpan pada file Excel di Jurusan. Dan data ini cenderung tidak terbaharui karena hanya dikelola di tingkat jurusan tanpa melibatkan alumni itu sendiri. Oleh karenanya dalam penelitian ini dikembangkan sebuah sistem informasi alumni sebagai database alumni untuk mengetahui status keterserapan alumni di dunia usaha dan industri. Sistem ini dikembangkan berbasis web agar bisa diakses oleh banyak orang, dan apabila ada perbaikan data terkait dengan alumni itu sendiri dapat dilakukan oleh yang besangkutan. Pengembangan sistem ini menggunakan model waterfall, yang merupakan model yang paling banyak digunakan dalam pengembangan sebuah perangkat lunak. Sistem Informasi Alumni ini mampu menangani pengelolaan data alumni yang meliputi: pengelolaan data identitas alumni, data keaktifan alumni sewaktu menjadi mahasiswa, data karir alumni, data kemaslahatan alumni, data organisasi alumni, dan pengelolaan data relevansi jurusan dengan pekerjaan saat ini.
\end{abstract}

Kata kunci: alumni, sistem informasi, basis data.

\section{Abstract}

Department of Informatic Management is one of the Department under the Faculty of Technical and Vocational Ganesha University of Education. From its establishment in 1999 until the end of 2007, this department has graduated about 290 people, and most have been absorbed in the world of business and industry, and some are absorbed as civil servants (PNS). So far, records or documentation of graduates is only done in private which means there is only the final record of the graduates that are stored on an Excel file in the Department. And these data tend not renewable because it only managed at department level without

Pelacakan Alumni (Tracer Study) Jurusan..............( Komang Setemen) 
involving the alumni themselves. Therefore, in this study was developed an alumny information system as database to find out the status of alumny in the world of business and industry. Webbased system was developed to be accessible by many people, and if there are improvements related to the alumny data itself can be done by themself. The development of this system using waterfall model, which is the most widely used model in developing a software. Alumny Information System is able to handle the data management of alumny that include: management of alumny identity, alumny activity as a student, alumny career, benefit of alumny, the alumny organization, and management of relevance of department with the current job.

Keyword: alumny, information system, database.

\section{Pendahuluan}

Perkembangan Teknologi Informasi dan Komunikasi atau yang lebih populer dikenal ICT (Information and Communication Tecnology) yang begitu pesat selalu sertai dengan perkembangan dari sisi hardware maupun software. Berbagai lembaga pendidikan berlomba-lomba mengikuti perkembangan teknologi ini dengan melakukan investasi baik dalam infrastruktur, hardware maupun sistem informasi yang digunakan untuk mendukung operasional lembaga.

Universitas Pendidikan Ganesha (Undiksha) sebagai lembaga pendidikan telah banyak melakukan perbaikan dalam infrastruktur maupun pengembangan sistem-sistem informasi yang digunakan untuk mendukung kegiatan-kegiatan rutin di lingkungan kampus, seperti: sistem informasi kepegawaian, keuangan, kemahasiswaan, dan lain-lain. Undiksha sangat menaruh perhatian terhadap perkembangan ICT dan terapannya dalam sistem pembelajaran sebagai usaha peningkatan kompetensi untuk menjadi pusat keunggulan. Hal ini diwujudkan dengan dibentuknya Jurusan D3 Manajemen Informatika yang nantinya diharapkan dapat mengembangkan program konsolidasi kelembagaan berupa pemanfaatan ICT dalam sistem pembelajaran maupun dalam mendukung kegiatan-kegiatan rutin lembaga. 
Jurusan D3 Manajemen Informatika merupakan salah satu Jurusan di bawah Fakultas Teknik dan Kejuruan Universitas Pendidikan Ganesha. Dari sejak berdirinya tahun 1999 sampai dengan akhir tahun 2007, jurusan ini telah meluluskan kurang lebih 290 orang, dan sebagian besar telah terserap di dunia usaha dan industri, serta ada juga yang terserap sebagai pegawai negeri sipil (PNS). Sejauh ini, pencatatan atau dokumentasi lulusan hanya dilakukan secara tertutup yang artinya hanya ada catatan akhir dari para lulusan yang tersimpan pada file Excel di Jurusan. Dan data ini cenderung tidak terbaharui karena hanya dikelola di tingkat jurusan tanpa melibatkan alumni itu sendiri. Di lihat dari kenyataan ini, meskipun ICT sudah diterapkan baik dari sisi pembelajaran maupun dalam hal mendukung kegiatan-kegiatan rutin di lembaga, tetapi dalam pengelolaan data alumni masih belum tersentuh oleh pemanfaatan ICT secara maksimal. Oleh karena itu, melalui penelitian ini akan dilakukan pengembangan sistem informasi yang berbasis ICT sebagai database pelacakan alumni, agar data yang ada selalu terbaharui sehingga bisa dijadikan tolak ukur kompetensi lulusan yang dibutuhkan oleh pasar kerja.

Dari latar belakang yang telah diuraikan di atas maka permasalahan dapat dirumuskan sebagai berikut : "Bagaimana pengembangan sistem informasi yang berbasis ICT sebagai database Pelacakan Alumni Jurusan Manajemen Informatika?". Untuk memberikan ketegasan akan cakupan dari penelitian ini, maka perlu ditetapkan batasan penelitian sebagai berikut: (1) Sistem Informasi ini akan dikembangkan dalam bentuk Website dan di Hosting dengan domain sendiri (2) Data awal yang dimasukkan dalam system informasi ini adalah data sementara yang ada pada Jurusan Manajemen Informatika (3) Akan dilakukan sosialisasi sistem informasi kepada seluruh mahasiswa yang akan lulus, sehingga sistem informasi ini bisa dimanfaatkan secara optimal.

Pelacakan Alumni (Tracer Study) Jurusan................( Komang Setemen) 
Adapun tujuan dari penelitian ini adalah untuk mengembangkan sistem informasi yang berbasis ICT sebagai database Pelacakan Alumni Jurusan Manajemen Informatika, sehingga bisa dijadikan sarana untuk pengelolaan data alumni dengan data yang selalu terbaharui. Diarapkan dengan tersedianya sistem informasi yang berbasis ICT tentang data alumni, akan dapat dijadikan tolak ukur kompetensi lulusan yang dibutuhkan oleh pasar kerja.

Perkembangan ICT yang pesat dimulai dengan ditemukannya sebuah perangkat yang bernama komputer di era 60 - 70 an. Seiring dengan kebutuhan akan kemampuan pengolahan data, dibutuhkan kemampuan perangkat keras dan perangkat lunak yang memadai. Walaupun mungkin bila kita bandingkan, perkembangan inovasi di bidang perangkat lunak lebih cepat dari pada perangkat keras. ICT merupakan "bahan bakar" ekonomi digital atau ekonomi berbasis pengetahuan. Kita dapat menyebutnya sebagai bahan bakar mengingat perannya yang sangat vital dalam kegiatan perkonomian masa kini. Kita bisa bayangkan bagaimana seandainya saat ini tidak digunakan Electronic Data Processing (EDP), Management Information System (MIS), Executive Information System (EIS), ataupun Expert System (ES) dalam kegiatan-kegiatan sehari-hari yang semakin kompleks. (Hasibuan, 2007)

ICT juga memungkinkan tumbuhnya inovasi-inovasi baru. Dengan kehadiran ICT orang akan terus berupaya untuk menciptakan temuantemuan baru tertentu dengan tujuan utama: bagaimana membuat proses bisnis berjalan efektif dan efisien serta mampu meningkatkan produktivitas suatu organisasi atau perusahaan. Misalnya, walaupun ICT bukanlah core business dunia perbankan, tetapi tanpa ICT, boleh dikatakan sulit bagi suatu bank mampu bersaing dengan bank yang lain. Salah satu contoh kongkritnya adalah bagaimana kartu ATM bisa digunakan tanpa dibatasi oleh kendala geografis dan waktu. Hal ini menunjukkan bahwa bidang ICT bukan saja suatu bidang yang sifatnya 
strategis di industri ICT, tetapi juga ICT memiliki peran yang vital diberbagai sektor industri lainnya, terutama untuk meningkatkan efisiensi, efektivitas, dan produktivitas suatu organisasi.

World Wide Web (WWW) atau yang lebih dikenal dengan nama web, merupakan salah satu layanan yang didapat oleh pemakai komputer yang terhubung ke internet, dan merupakan suatu perkembangan ICT yang sangat pesat. Web pada awalnya adalah ruang informasi dalam internet dengan menggunakan protocol yang dinamakan protocol HTTP (HyperText Tranfer Protocol). Pemakai dituntun untuk menemukan informasi dengan mengikuti link yang disediakan dalam dokumen web yang ditampilkan dalam browser web. Internet identik dengan web karena kepopuleran web sebagai standar interface dalam layanan-layanan yang ada di internet, dari awalnya sebagai penyedia informasi, kini digunakan juga untuk komunikasi dari email sampai dengan chatting dan melakukan transaksi bisnis (Commerce). (Beta Sidik, 2001).

\section{Metode Penelitian}

Penelitian ini merupakan penelitian rekayasa sistem perangkat lunak, sehingga dalam pelaksanaan penelitian ini, digunakan metodologi standar dalam pengembangan perangkat lunak. Metodologi yang digunakan adalah prosedur Life Cycle System yang dikenal dengan waterfall model yang merupakan metodologi tertua dan terbanyak digunakan dalam pengembangan perangkat lunak. Tahapan aktifitas dalam metode tersebut meliputi (1) penentuan kebutuhan sistem, (2) penentuan kebutuhan perangkat lunak (3) analisis (4) desain perangkat lunak (5) coding (6) uji coba (7) pengoperasian (8) perawatan (Edward Yourdon, 1989). Tahapan aktifitas yang dilakukan dalam prosedur implementasi perangkat lunak ini merupakan modifikasi dari tahapantahapan prosedur Life Cycle System di atas, meliputi :

1) Tahap Pengumpulan Data (System Requirement)

2) Tahap Analisis (Analysis) 
3) Tahap Desain/Perancangan (Design)

4) Tahap Pengembangan (Development / Coding)

5) Tahap Uji Coba (Testing)

6) Tahap Penerapan (Implementasi)

Penelitian ini dilakukan di Jurusan Manajemen Informatika, untuk proses pengembangan sistemnya. Dan beberapa Instansi pemerintah maupun swasta yang ada di Bali, untuk pengambilan data yang merupakan tempat bekerja dari para alumni. Subyek pada penelitian ini adalah Jurusan Manajemen Informatika yang ada di Fakultas Teknik dan Kejuruan. Dan populasi dari penelitian ini adalah data alumni dari Jurusan Manajemen Informatika. Desain penelitian yang merupakan modifikasi dari tahapan-tahapan dalam prosedur Life Cycle System, adalah seperti pada Gambar 3.1 berikut.

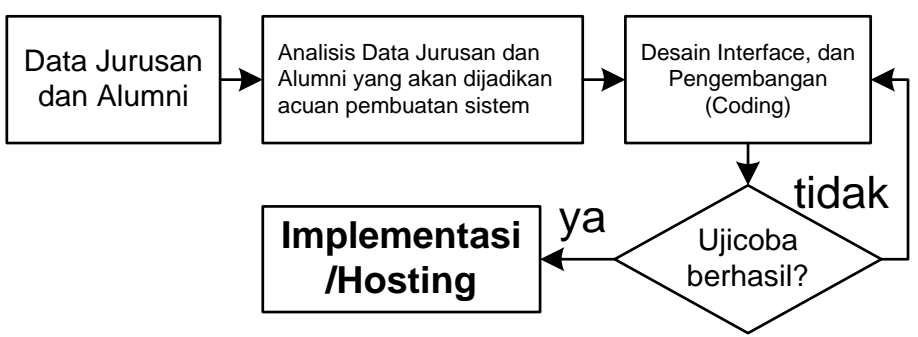

Gambar 3.1. Desain Penelitian

Analisis yang dilakukan disini adalah analisis terhadap hasil ujicoba sistem yang telah dihasilkan. Komponen analisis meliputi proses validasi terhadap masukan-masukan data yang menjadi komponen sistem. Selain validasi terhadap data masukan, yang paling penting pada analisis ini adalah kemampuan untuk menghasilkan infomasi sesuai dengan kebutuhan pengguna. Apabila pada analisis ini tidak ada kesalahan, maka perangkat lunak siap untuk di implementasikan. Dan jika sebaliknya, masih ada masalah pada analisis, maka perlu dilakukan perbaikan baik pada proses desain interface atau pada proses pengembangan (coding), maupun pada proses analisis data jurusan dan alumni. 


\section{Hasil dan Pembahasan}

\subsection{Proses Pengembangan Sistem}

Proses pengembangan sistem yang dilakukan dalam Sistem Informasi Alumni ini mengacu pada bab sebelumnya pada metodologi penelitian. Dimana pada metodologi penelitian disebutkan bahwa tahapan-tahapan yang dilakukan dalam pengembangan sistem meliputi: (1) Tahap Pengumpulan Data, (2) Tahap Analisis, (3) Tahap Desain/Perancangan, (4) Tahap Pengembangan, (5) Tahap Uji Coba. Berikut akan dijelaskan proses dari masing-masing tahapan tersebut.

\subsubsection{Tahap Pengumpulan Data}

Pengumpulan data dilakukan dengan mendata sebanyak mungkin alumni mulai dari tahun 2001 sampai dengan tahun 2008, dengan menyebarkan Quisioner yang harus diisi oleh alumni. (Lampiran 1). Dari data yang terkumpul selanjutnya dibuatkan dalam bentuk tabel yang akan dimasukkan dalam database alumni. Pemilahan data berdasarkan hasil Quisioner yang disebarkan tersebut selanjutnya akan dianalisis seperti pada tahap berikutnya.

\subsubsection{Tahap Analisis Data}

Pada tahap ini akan dilakukan analisa terhadap data yang sudah terkumpul pada tahap sebelumnya. Analisa yang dimaksud adalah pemilahan terhadap kumpulan data sehingga akan lebih mudah dalam proses perancangan sistemnya. Hasil pengumpulan data yang telah diperoleh dari tahap sebelumnya, kemudian dipilah menjadi bagianbagian data yang lebih kecil. Adapun bagian-bagian data yang dimaksud adalah: (1) Data Identitas Alumni, (2) Data Keaktifan Berorganisasi, (3) Data Karir, (4) Data Kemaslahatan, (5) Data Organisasi, (6) Data Relevansi, dan (7) Data Pekerjaan. 


\subsubsection{Tahap Perancangan}

Tahan perancangan merupakan tahap perancangan sistem berdasarkan hasil analisis data pada tahap sebelumnya. Pada tahap ini akan dijelaskan aliran data dari setiap proses pada Sistem Informasi Alumni ini, serta modul-modul yang digunakan pada tahap pengembangan atau coding. Perancangan sistem pada aplikasi ini akan digambarkan menggunakan Data Flow Diagram (DFD), yang merupakan salah satu bahasa pemodelan dalam perancangan sistem. DFD pada perancangan sistem ini akan digambarkan dengan diagram konteks dan DFD Level 0 saja, karena sampai dengan DFD Level 0, aliran data dari dan ke entitas dalam sistem aplikasi ini sudah cukup jelas. Diagram konteks dan DFD Level 0 dari Sistem Informasi Alumni ini seperti pada Gambar 4.1 dan Gambar 4.2 berikut.

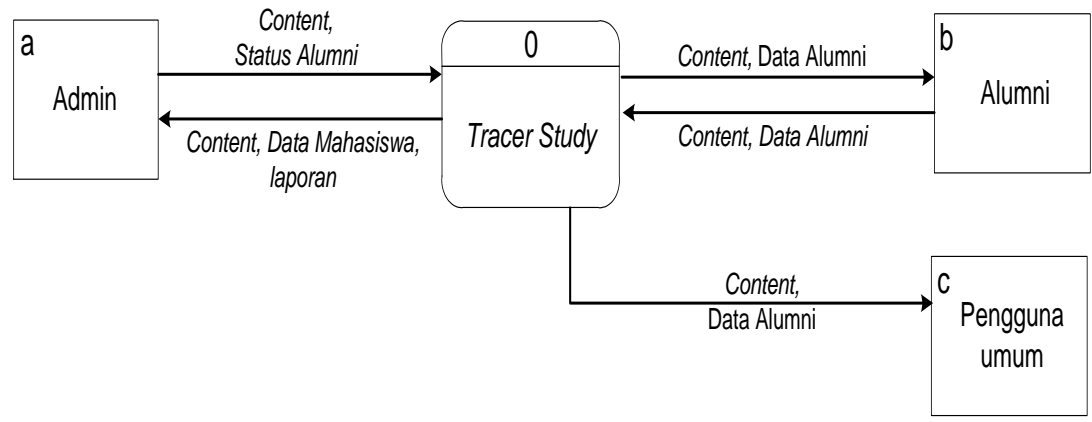

Gambar 3.1 Diagram Konteks Sistem Informasi Alumni 


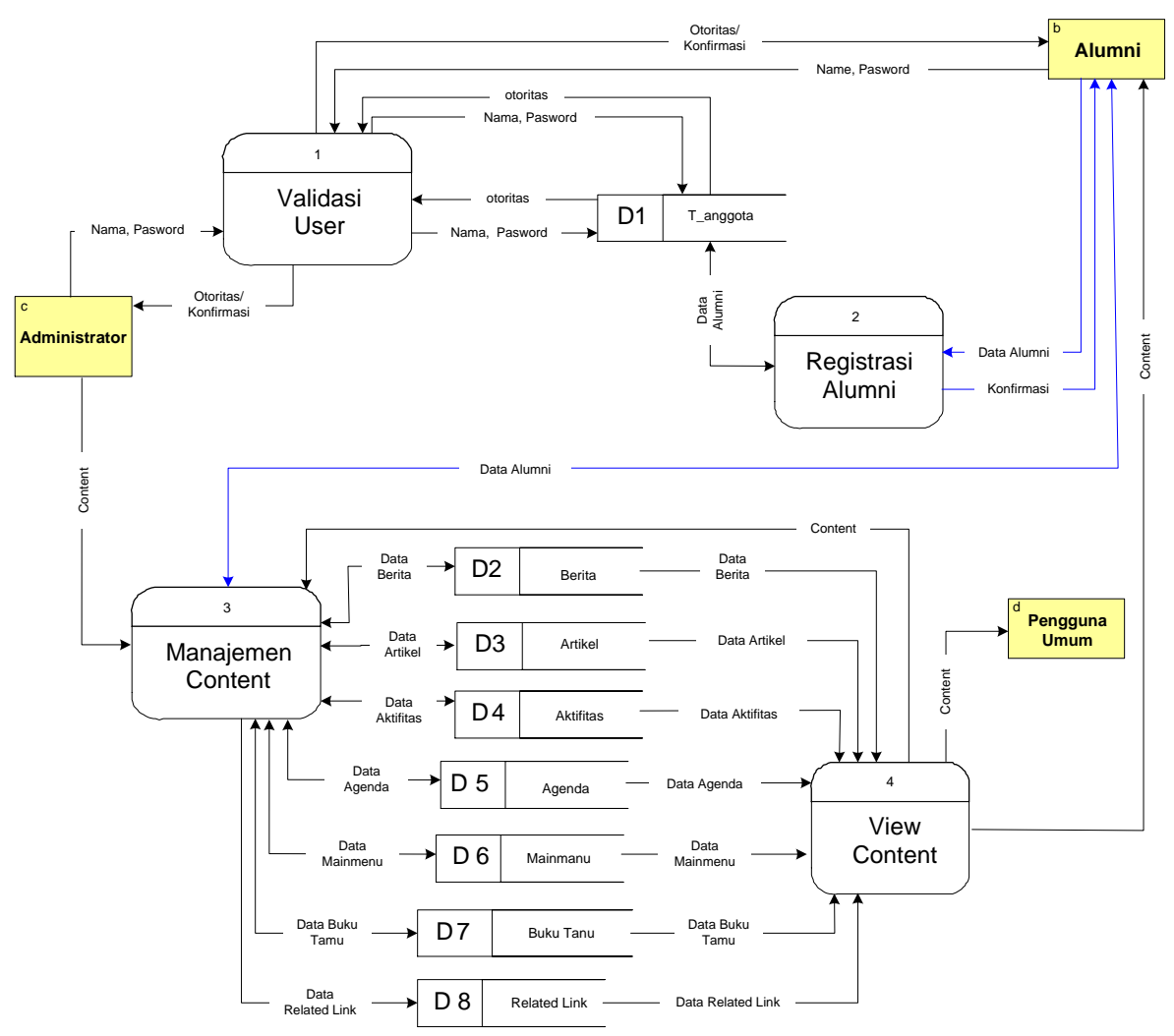

Gambar 3.2 DFD Level 0 Sistem Informasi Alumni

\subsubsection{Tahap Pengembangan}

Tahap pengembangan merupakan tahap untuk mengkonversi hasil desain ke dalam sistem yang akan digunakan. Tahap pengembangan ini terdiri dari dua bagian, yaitu: pengembangan interface, dan pengembangan kode program untuk proses-proses yang berkaitan dengan input dan output. Sistem ini dikembangkan dengan database MySQL 5.0 dan bahasa script PHP.

\subsubsection{Tahap Pengembangan Interface}

Untuk menampilkan hasil desain sistem, dibuat antar muka antara pemakai dengan sistem. Perancangan antar muka ini dibuat dengan menggunakan Adobe Pothosop, Macromedia Dreamweaver, Script PHP dan database MySQL Server 5.0 dengan sistem operasi Windows XP 
Professional. Hasil perancangan antar muka seperti pada bagian-bagian berikut.

\section{Perancangan Antar Muka Halaman Utama}

Halaman muka dari Sistem Informasi Alumni ini adalah seperti pada Gambar 4.3. berikut, yang dapat diakses langsung dari internet melalui alamat website http://www.undiksha.ac.id/informatika.

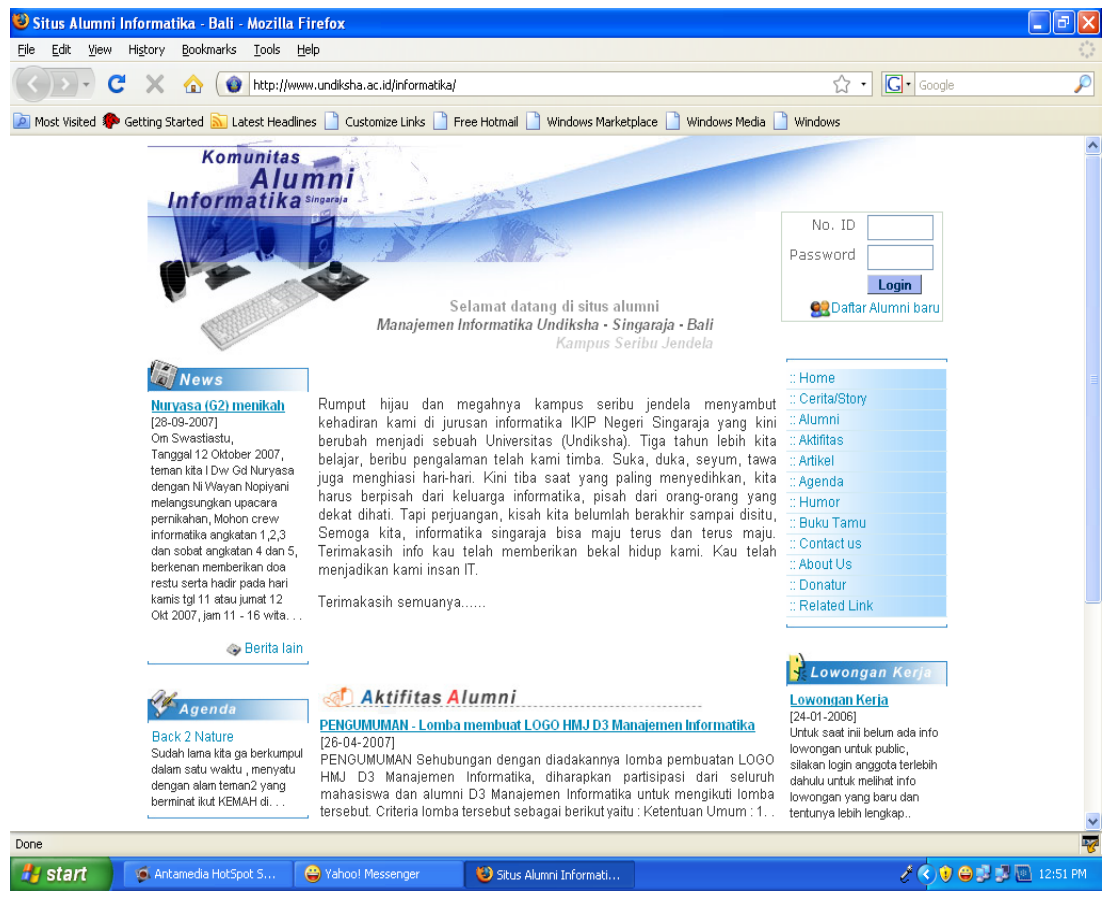

Gambar 3.3 Tampilan Utama Sistem Informasi Alumni

\section{Halaman Antar Muka Memasukkan Data Alumni}

Untuk memasukkan data alumni, dapat dilakukan dengan mengklik menu alumni. Melalui antar muka ini, alumni dapat mengisikan data dirinya sesuai dengan form inputan yang sudah disediakan. Antar muka dari input data alumni ini seperti pada Gambar 4.4 berikut. 


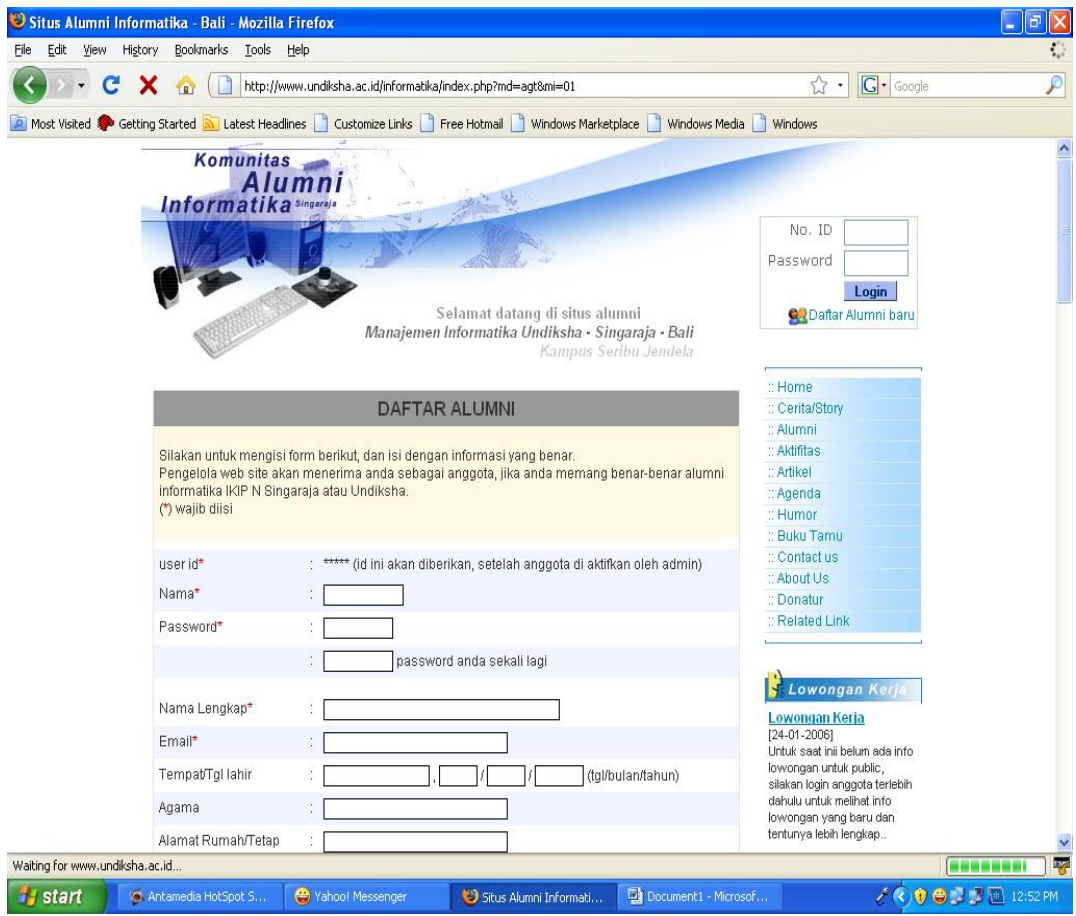

Gambar 3.4 Tampilan Input Data Alumni

\section{Halaman Antar Muka Melihat Data Alumni}

Antar muka lihat data alumni adalah antar muka yang berfungsi sebagai form untuk melihat data alumni secara detil, ataupun melakukan pencarian data alumni berdasarkan nama alumni atau tahun angkatan masuka alumni. Dengan fasilitas ini diharapkan pemakai dapat memperoleh informasi yang diperlukan terkait dengan alumni Jurusan Manajemen Informatika. Antar muka dari form lihat alumni ini seperti pada Gambar 4.5 berikut. 


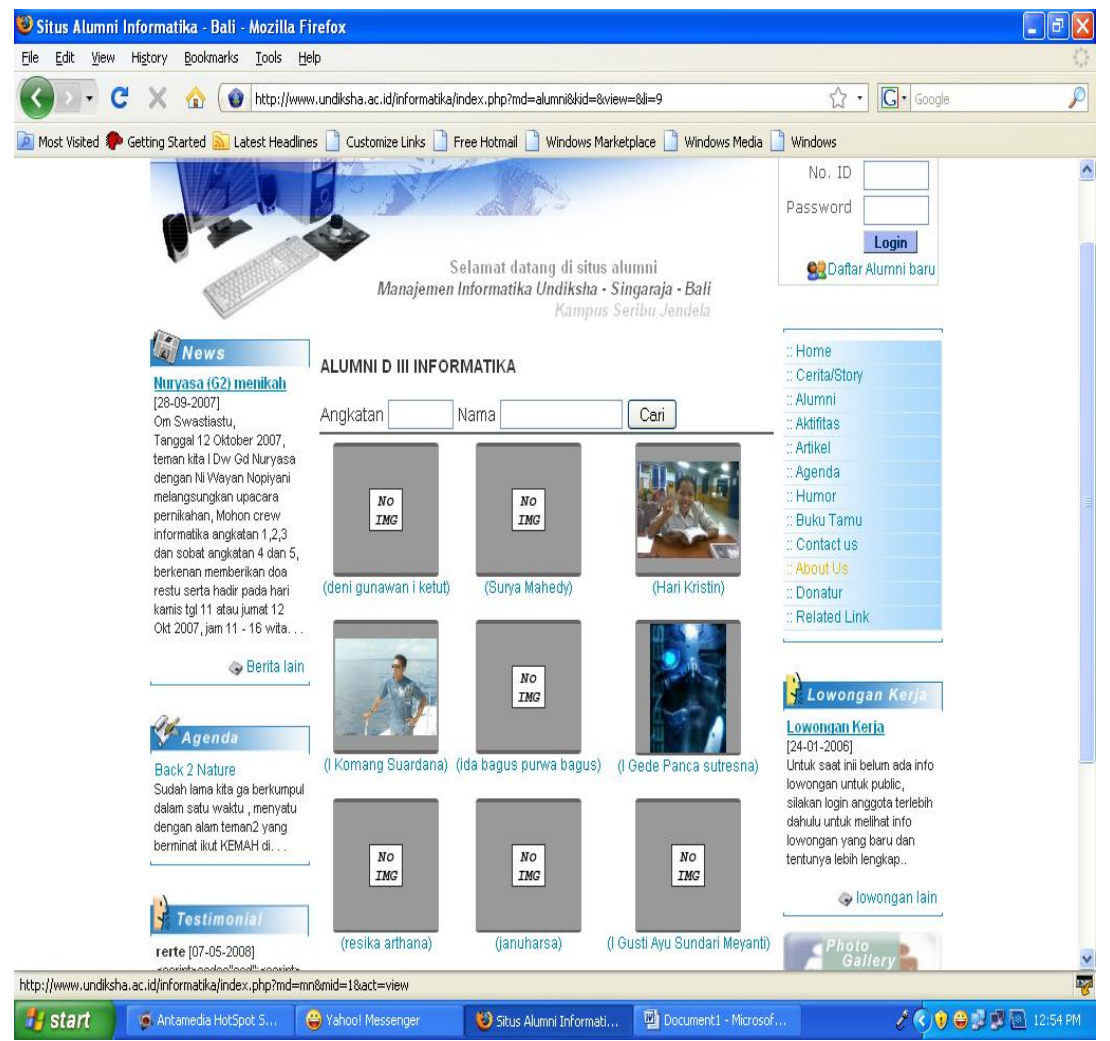

Gambar 3.5 Tampilan Lihat Data Alumni

\section{Penutup}

Beberapa simpulan yang dapat diambil dari analisa dan pengembangan sistem informasi yang berbasis ICT sebagai database Pelacakan Alumni Jurusan Manajemen Informatika adalah:

1. Sistem Informasi Alumni ini mampu menangani pengelolaan data Alumni yang meliputi: (a) Pengelolaan data identitas alumni, (b) Pengelolaan data keaktifan alumni sewaktu menjadi mahasiswa, (c) Pengelolaan data karir alumni, (d) Pengelolaan data kemaslahatan alumni, (e) Pengelolaan data organisasi alumni, (f) Pengelolaan data relevansi jurusan dengan pekerjaan saat ini, dan (g) Pengelolaan data pekerjaan saat ini dari alumni 
2. Dengan dikembangkannya Sistem Informasi Alumni ini dalam bentuk Website, maka semua informasi tentang alumni Jurusan Manajemen Informatika dapat diakses oleh semua pihak yang membutuhkan terutama para stakeholders.

3. Sistem Informasi Alumni ini dapat memberikan gambaran kepada Lembaga khususnya bagi Jurusan Manajemen Informatika, yang berkaitan dengan keterserapan lulusan di dunia kerja.

Adapun saran yang dapat diberikan guna penelitian lebih lanjut tentang Sistem Informasi Alumni ini adalah, bahwa masih banyak informasi yang perlu ditambahkan seperti grafik lulusan dalam memperoleh pekerjaan, layanan e-mail, dan fasilitas chatting, guna memberikan fasilitas lebih pada pemakai dari sistem.

\section{DAFTAR PUSTAKA}

Didik Dwi Prasetyo. 2004. Solusi Pemrograman Berbasis Web Menggunakan PHP5. Elex Media Komputindo Kelompok Gramedia:Jakarta.

Edward Yourdon, 1989. Modern Structured Analysis. New Jersey : Prentice - Hall International, Inc.

Kadir Abdul. 2001. Dasar Pemrograman Web Dinamis Menggunakan PHP. Andi:Yogyakarta.

Mulyana. 2004. Trik Membangun Situs Menggunakan PHP dan My SQL. Elex Media Komputindo Kelompok Gramedia:Jakarta.

Nugroho Bunafit. 2004. Perancangan Web dengan Fireworks dan Dreamweaver MX. Gava Media:Yogyakarta.

Sumartini. 2005. Pengantar Kearsipan.

Thabrani Suryanto. 2005. Web Statis dan Dinamis dengan Dreamweaver 8. Elex Media Komputindo Kelompok Gramedia:Jakarta. 
Wikipedia.Web. http://id.wikipedia.org/wiki/WorldWideWeb.28-April 2007.

Zainal Hasibuan, 2007. Kontribusi Dunia Pendidikan dalam Bidang Teknologi Informasi untuk Dunia Usaha/Industri. Makalah disampaikan pada Seminar Jurusan Manajemen Informatika tanggal 7 Mei 2007. 